\title{
Precision Measurement of Cylinder Surface Profile on an Ultra-Precision Machine Tool
}

\author{
J. C. Lee, Y.J. Noh, Y. Arai, W. Gao, C.H. Park ${ }^{1}$ \\ Nano-Metrology and Control Lab, Department of Nanomechanics, Tohoku University, \\ Aramaki Aza Aoba 6-6-01, Sendai, 980-8579, Japan, leejc@nano.mech.tohoku.ac.jp \\ ${ }^{1}$ Korea Institute of Machinery and Materials, \\ Sinseongno Yuseong-Gu, Deajeon, South Korea, pch657@kimm.re.kr
}

\begin{abstract}
This paper describes the measurement of the surface straightness profile of a cylinder workpiece on an ultra-precision machine tool which has a T-base design with a spindle, an $X$-slide and a Z-slide. The movement range of the $X$-slide is $220 \mathrm{~mm}$ and that of the $Z$ slide is $150 \mathrm{~mm}$, which have roller bearings in common. Two capacitive sensors are employed to scan a cylinder workpiece mounted on the spindle along the Z-axis. The straightness error motion of the Z-slide is measured to be approximately $100 \mathrm{~nm}$ by the reversal method. The straightness profile of the cylinder workpiece is evaluated to be approximately $400 \mathrm{~nm}$ by separation of the motion error, simultaneously.
\end{abstract}

Keywords: Measurement, Surface Profile, Error Motion, Straightness, Machine Tool, Slide, Reversal Method

\section{INTRODUCTION}

$\mathrm{U}$ LTRA-PRECISION machine tools are widely used in fabrication of various workpieces such as optical components with three dimensional microstructures. [1][3] However, the motion error of an ultra-precision machine tool causes profile errors when precisely fabricating the workpiece. It is thus necessary to measure the motion error of the ultra-precision machine tool for evaluation of the machine tool and surface profile of workpiece. Usually, a high precision gauge is needed for the measurement of the error motion. On the other hand, it is desired to measure the surface profile of the workpiece on the machine tool from the view point of machining efficiency. [4]-[6] For this purpose, it is desired to measure the motion error of the machine tool and the surface profile of the workpiece simultaneously. In this research, a cylinder workpiece machined on an ultra-precision machine tool is used as the measurement target for simultaneous measurement of the error motion and the surface profile. To separate the two parameters from the sensor output, the reversal technique is employed. By using this method, both the error motion and the surface profile can be measured with a high precision. But the reversal method is only effective to measure two profiles of a workpiece. To overcome the shortcoming of the reversal method, the rotating reversal method is proposed. This paper presents the principle of the reversal method and the rotating reversal method that uses high-precision capacitive sensors. Experimental results on an ultra-precision diamond turning machine are also described.

\section{PRINCIPLE OF MEASUREMENT}

\subsection{The reversal method}

The reversal method can be applicable for measurement of surface profile and error motion when the machine motion has a high repeatability [7]. The ultra-precision machine tool can satisfy this requirement because the motion of the machine tool slide is repeatable on the order of $10 \mathrm{~nm}$. In this method, it is necessary to rotate the workpiece by 180 degrees and carry out two scans before and after the rotation (reversal).

\section{Before reversal}

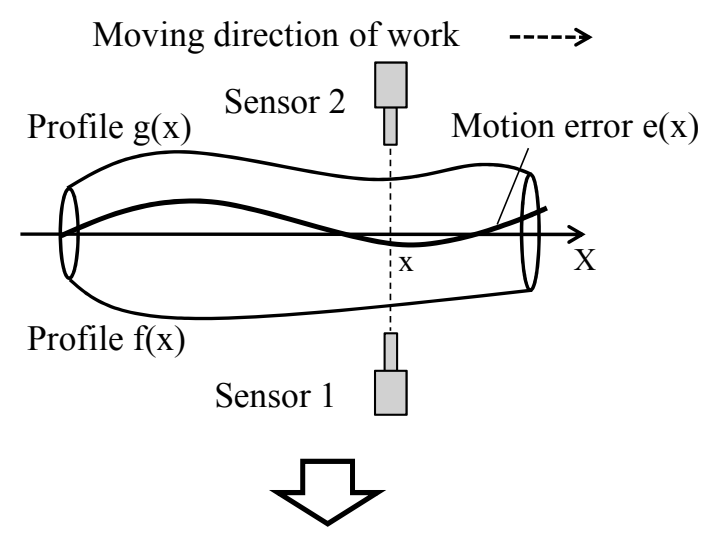

After reversal

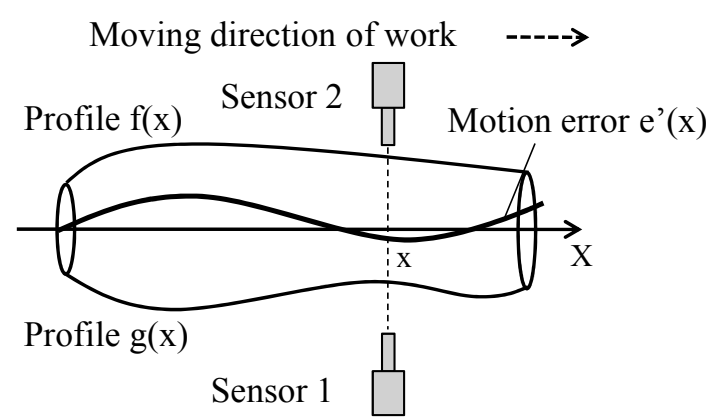

Fig.1 Principle of the reversal method

Fig. 1 shows the principle of the measurement by the reversal method. In the first scanning, two displacement sensors are employed to scan the workpiece before the reversal. The sensor outputs can be written as 
where

$$
\begin{aligned}
& m_{A 1}(x)=f(x)+e(x) \\
& m_{B 1}(x)=g(x)-e(x)
\end{aligned}
$$

$\mathrm{m}_{\mathrm{A} 1}$ sensor output of the sensor 1 before reversal $\mathrm{m}_{\mathrm{B} 1}$ sensor output of the sensor 2 before reversal $\mathrm{e}(\mathrm{x})$ motion error of the slide before reversal $\mathrm{f}(\mathrm{x})$ profile of the cylinder on the side of sensor 1 $\mathrm{g}(\mathrm{x})$ profile of the cylinder on the side of sensor 2

When the workpiece is moved along the $\mathrm{X}$-axis once again after the reversal, the sensor outputs are changed as follows

where

$$
\begin{aligned}
& m_{A 2}(x)=g(x)+e^{\prime}(x) \\
& m_{B 2}(x)=f(x)-e^{\prime}(x)
\end{aligned}
$$

$\mathrm{m}_{\mathrm{A} 2}$ sensor output of the sensor 1 after reversal $\mathrm{m}_{\mathrm{B} 2}$ sensor output of the sensor 2 after reversal $\mathrm{e}^{\prime}(\mathrm{x})$ motion error of the slide after reversal

From the above equations, the motion error $\mathrm{e}(\mathrm{x})$ and the surface profiles $\mathrm{f}(\mathrm{x}), \mathrm{g}(\mathrm{x})$ can be calculated as follows

$$
\begin{aligned}
& e(x)=\frac{\left(m_{A 1}(x)-m_{B 2}(x)\right)}{2}+\Delta e(x) \\
& f(x)=\frac{\left(m_{A 1}(x)+m_{B 2}(x)\right)}{2}+\Delta e(x) \\
& g(x)=\frac{\left(m_{B 1}(x)+m_{A 2}(x)\right)}{2}+\Delta e(x)
\end{aligned}
$$

where

$$
\Delta e(x)=\frac{\left(e(x)-e^{\prime}(x)\right)}{2}
$$

Equation (8) can be ignored because the motion of the ultra precision machine tool has a high repeatability. Therefore, the motion error and profiles can be calculated in equations (5)-(7) without considering $\Delta \mathrm{e}(\mathrm{x})$.

\subsection{The rotating reversal method for $3 d$ surface profile measurement of the cylinder workpiece}

The reversal method is used for measurement of the motion error of the slide and two sectional profiles of the cylinder surface. However, the reversal method is not enough for measurement of the three dimensional (3D) surface profile of the cylinder workpiece because the cylinder 3D profile measurement demands a number of sectional profiles. Thus, a rotating reversal method is proposed for the cylinder 3D profile measurement. Fig. 2 shows a schematic of the rotating reversal method. The cylinder workpiece is rotated by the spindle and moved along the X-direction. As can be seen in Fig.2, two-sensor outputs, when they scan the cylinder workpiece while the cylinder workpiece is being rotated, are taken in a spiral manner. Fig.3 shows the traces of the sensors on the workpiece surfaces. As shown in the figure, the pitch can be written as where

$$
P=N \cdot S
$$

$\mathrm{P}$ pitch of one rotation

$\mathrm{N}$ a number of profiles

$\mathrm{s}$ scanning interval

The surface profiles of the cylinder can be expressed in 3D expression based on the above equation as

$$
\begin{gathered}
f\left(x_{i, j}\right)=m_{A}(i \cdot s+j \cdot P) \\
f\left(x_{i+N / 2, j}\right)=m_{B}(i \cdot s+j \cdot P)
\end{gathered}
$$

where

i angular factor by rotation $(0,1,2 \cdots)$

$\mathrm{j}$ direction factor by moving $(0,1,2 \cdots)$

$f\left(x_{i, j}\right)$ profile of the cylinder on the side of sensor 1

$\mathrm{f}\left(\mathrm{x}_{\mathrm{i}+\mathrm{N} / 2, \mathrm{j}}\right)$ profile of the cylinder on the side of sensor 2

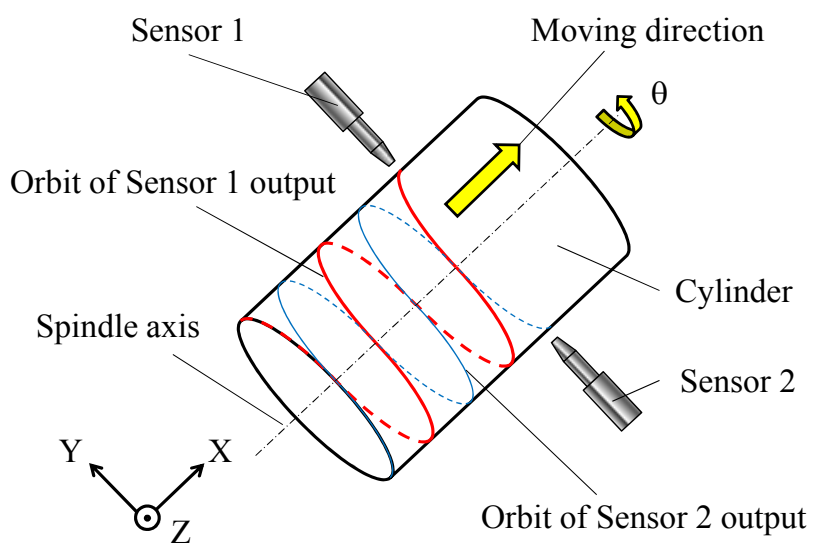

Fig.2 Schematic of the rotating reversal method

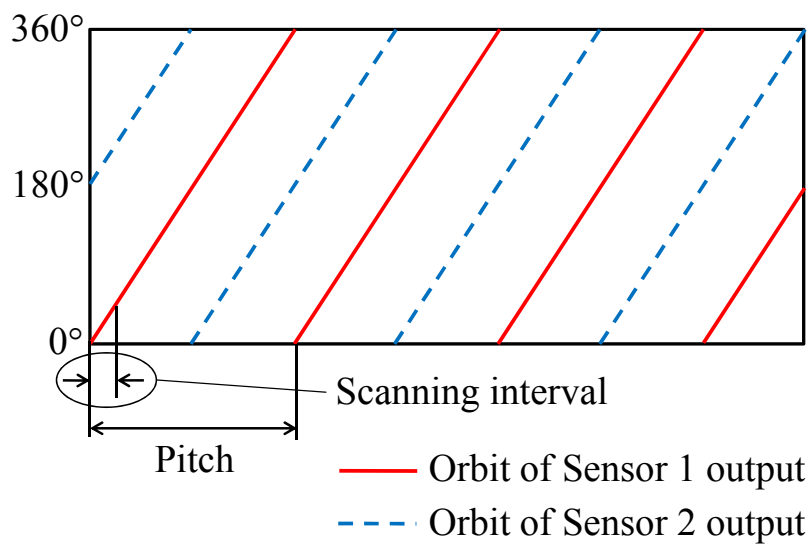

Fig.3 Orbits of sensor outputs of the rotating reversal method

Similarly, the surface profiles of the cylinder after the reversal can be expressed as 


$$
\begin{array}{r}
f\left(x_{i, j}\right)=\frac{\left(m_{A 1}(i \cdot s+j \cdot P)+m_{B 2}(i \cdot s+j \cdot P)\right)}{2} \\
f\left(x_{i+N / 2, j}\right)=\frac{\left(m_{B 1}(i \cdot s+j \cdot P)+m_{A 2}(i \cdot s+j \cdot P)\right)}{2}
\end{array}
$$

From Equations (12) and (13), the 3D surface profiles of the cylinder workpiece can then be calculated.

\section{EXPERIMENTS}

Fig.4 shows the experimental system for measurement of the Z-slide straightness of an ultra-precision machine tool and the surface straightness of the cylinder workpiece. Two capacitive sensors were employed in the measurement. Each of the displacement sensors had a measurement range of 100 $\mu \mathrm{m}$, a resolution of $1 \mathrm{~nm}$, a bandwidth of $40 \mathrm{kHz}$ and a foot print size of $1 \mathrm{~mm}$. The analog output of the displacement sensor was acquired by a personal computer via a 16 bit analog-to-digital board. The sensor outputs were acquired by synchronizing them with the signal from a linear encoder which was used to provide the accurate position of the Z-slide. On the other hand, the Z-slide of the machine tool had a 150 $\mathrm{mm}$ stroke, a positioning resolution of $10 \mathrm{~nm}$, and a positioning accuracy of $\pm 50 \mathrm{~nm}$. The air spindle had $50 \mathrm{~nm}$ rotational accuracies in the radial direction and the axial direction, respectively. Fig. 6 shows the results of the stability test, in which the machine tool was kept stationary. The test time was $10 \mathrm{~min}$, and the sampling interval was $10 \mathrm{~ms}$. As can be seen in the figure, the instability was measured to be $50 \mathrm{~nm}$, which includes low-frequency components caused by thermal drift of the mechanical structure of the slide and long-term instability of the air pressure. The high-frequency components of the data came from the vibration of the machine tool. The cylinder workpiece was moved by the Z-slide for straightness measurement. The two capacitive sensors, which were kept stationary on the machine tool, scanned the cylinder workpiece while the workpiece was rotated by the spindle. After reversal of the workpiece by 180 degrees, the workpiece was moved along the $\mathrm{Z}$-axis once again. The reversal of the workpiece was carried out by the air-spindle. The length of measurement was $126 \mathrm{~mm}$, the moving speed was $1 \mathrm{~mm} / \mathrm{s}$, the sampling interval was $5 \mu \mathrm{m}$ and the pitch was $180 \mu \mathrm{m}$ because the number of profiles was 36 . The straightness error of the Zslide was measured to be approximately $100 \mathrm{~nm}$. Fig.7 shows the evaluated sectional profiles of the cylinder workpiece by separation of the motion error. As shown in Fig.7, there was little difference between profile of $\mathrm{f}(\mathrm{x})$ and $\mathrm{g}(\mathrm{x})$ because the workpiece was a cylinder which was fabricated by the ultraprecision machine tool. The cylinder workpiece had a profile error of approximately $400 \mathrm{~nm}$. Fig. 8 shows the 3D surface profiles of the cylinder workpiece, which were measured by the rotating reversal method. As shown in the figure, the cylinder had a taper shape with a variation of about $400 \mathrm{~nm}$ in the profile over the length of $126 \mathrm{~mm}$. The taper-shaped surface profile was mainly generated by the motion error of the slide.

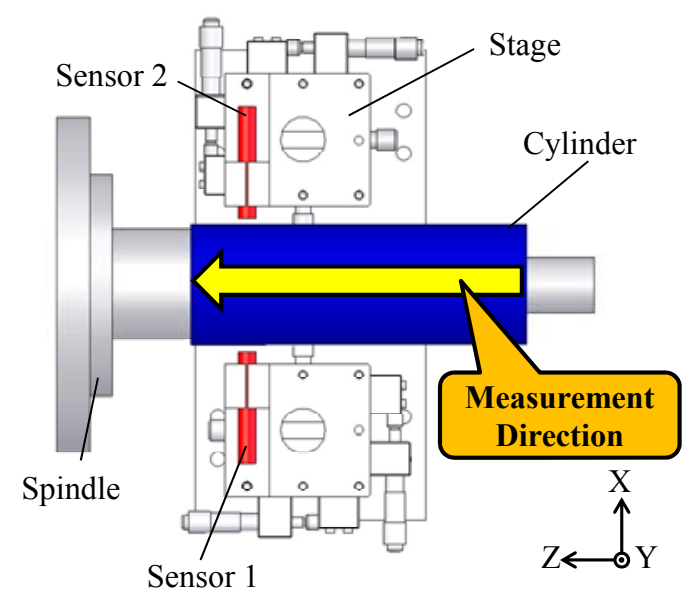

Fig.4 Experimental system

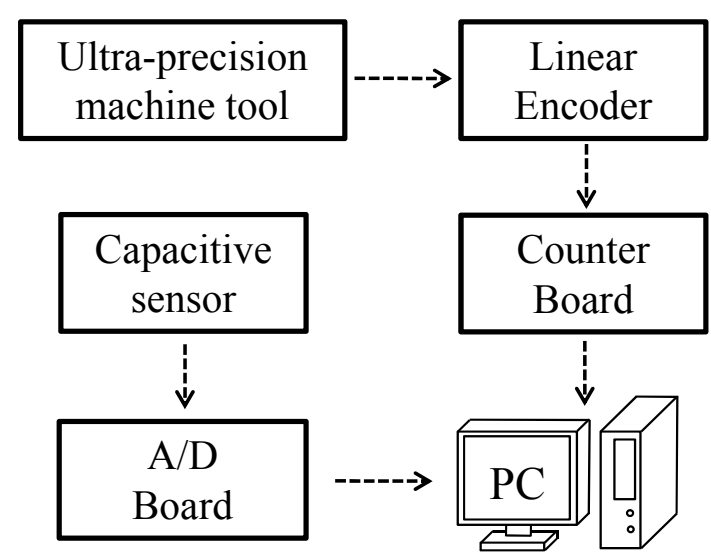

Fig.5 Diagram of experimental setup

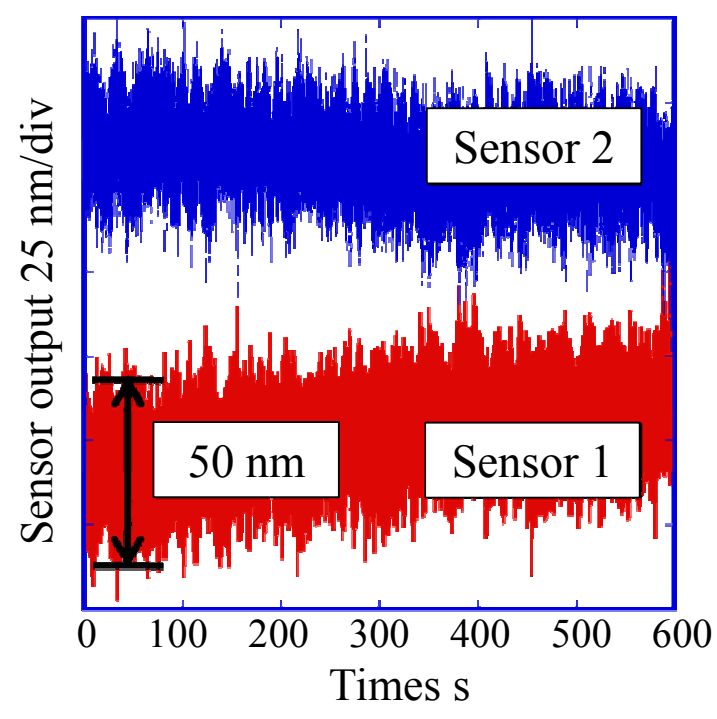

Fig.6 Stability of sensor 


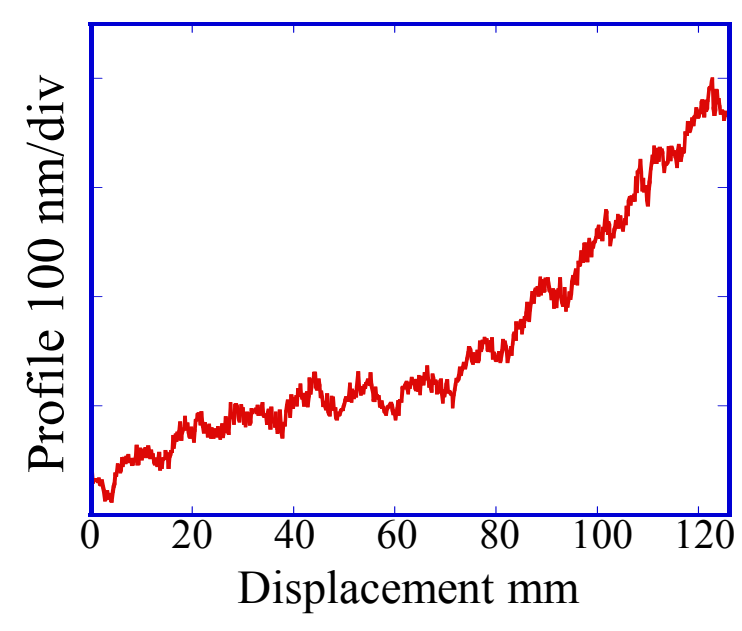

(a) profile of $f(x)$

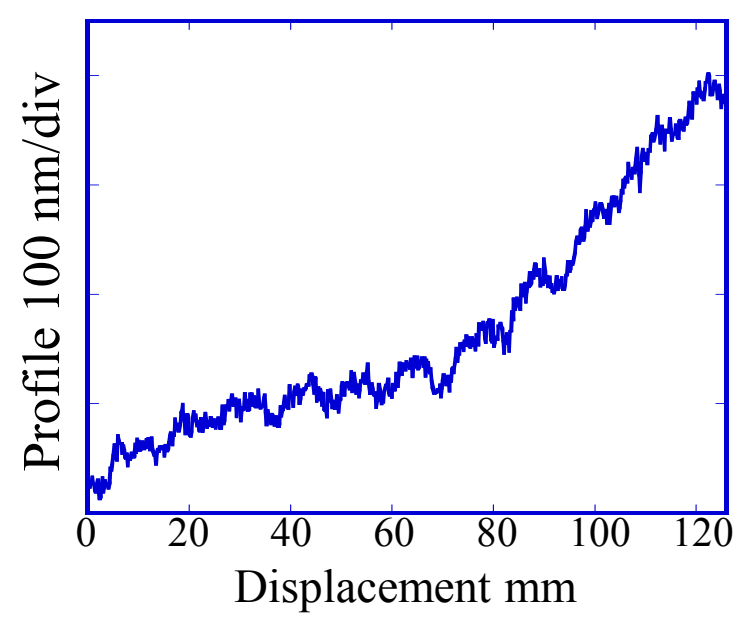

b.) profile of $\mathrm{g}(\mathrm{x})$

Fig.7 Evaluated profile

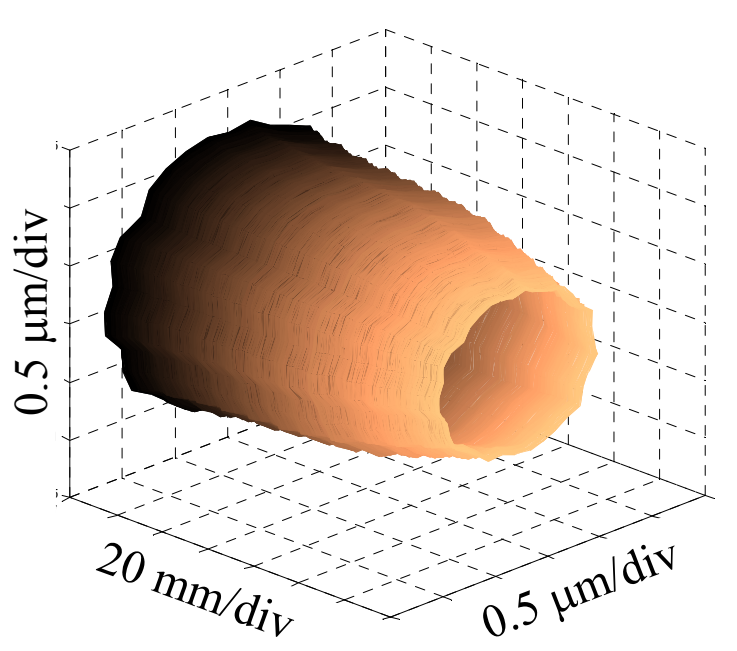

Fig.8 Cylinder profiles

\section{CONCLUSIONS}

A measurement system that can measure the surface profile of a cylinder workpiece and the motion error of an ultraprecision machine tool at the same time has been established. It was confirmed that the straightness error of the Z-slide of the machine tool was approximately $100 \mathrm{~nm}$ and the straightness profile of the workpiece was measured to be approximately $400 \mathrm{~nm}$ by the reversal method. A rotating reversal method has also been proposed for measurement of the $3 \mathrm{D}$ profile of the cylinder workpiece.

\section{REFERENCES}

[1] Tanaka, K. et al. (2007). Development of an ultraprecision machine tool. Journal of Japan Society for Abrasive Technology, 51, 553-558.

[2] Gao, W. (2005). Precision nanometrology and its appications to precision nanosystems. International Journal of Precision Engineering and Manufacturing, 6, 14-20.

[3] Kiyono, S., Gao, W. (1994). Profile measurement of machined surface with a new dirrerential method. Precision Engineering, 16, 212-218.

[4] Jywe, W., Chen, C.-J. (2007). A new 2D error separation technique for performance tests of $\mathrm{CNC}$ machine tools. Precision Engineering, 31, 369-375.

[5] Kono, D., Matsubara, A., Yamaji, I., Fujita, T. (2008). High-precision machining by measurement and compensation of motion error. International Journal of Machine Tools and Manufacture, 48, 1103-1110.

[6] Tanaka, H., Tozawa, K., Sato, H., O-hori, M., Sekiguchi, H. (1981). Application of a new straightness measurement method to large machine tool. Annals of the CIRP, 30, 455-459.

[7] Whitehouse, O.J. (1976). Some theoretical aspects of error separation techniques in surface metrology. Journal of Physics E: Science Instruments, 9, 531-536. 